\title{
キラル固定相と非キラル誘導体化試薬を用いる高速液体 クロマトグラフィーによる微量アミノ酸及びオキシ酸
}

の光学異性体分離

\author{
大井 尚文 ${ }^{\circledR *}$, 北 原 一*, 木須 直子* \\ (1994 年 11 月 14 日受付) \\ (1995 年 1 月 9 日審查終了)
}

\section{1 緒言}

高速液体クロマトグラフィー（HPLC）によるアミ， 酸及びオキシ酸の光学異性体分離において，キラルな配 位子の銅錯体を固定相として用いる直接分離法 ${ }^{1)}$ が優れ ていることは言うまでもないが，微量分析のためには検 出感度が不十分と言える. 著者ら ${ }^{2) \sim 4)}$ は，新しいキラ ル配位子の銅錯体を用いた HPLC によるアミノ酸及び オキシ酸光学異性体の直接分離において良好な結果を得 たが, 今回, 微量のアミノ酸及びオキシ酸の光学異性体 分離を目的として, HPLC に通常利用される高感度検 出のための非キラル誘導体化試薬とキラル固定相を組み 合わせる方法を検討した。

本研究では非キラル誘導体化試薬としてアミノ酸につ いてはダブシルクロライド5) (4-ジメチルアミノアゾベ ンゼン-4'-スルホニルクロライド) を，オキシ酸につい てはピレン-1-カルボニルニトリル6)を用いたが，これら は，それぞれアミノ基及び水酸基に対する吸光光度法及 び蛍光光度法による高感度検出用の誘導体化試薬として 有効なことが知られている。 一方，キラル固定相として

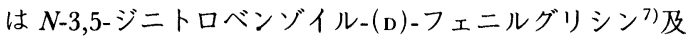

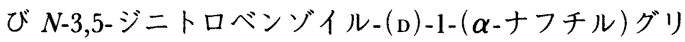
シン8)をアミノプロピルシリカに結合させたもの $[\mathrm{I}]$, [II] 並びに $(S)$-バリン, $(S)$-t-ロイシン及び $(\mathrm{D})$-フェ ニルグリシンの 3,5-ジニトロフェニル尿素誘導体 ${ }^{9}$ をア ミノプロピルシリカに結合させたもの [III]，[IV] 及 び [V] を用いたが，これらはいずれもカルボン酸類の 光学異性体分離に良好な性能を有することが報告されて いる.

* (株)住化分析センター: 554 大阪府大阪市此花区春日 出中 3-1-135
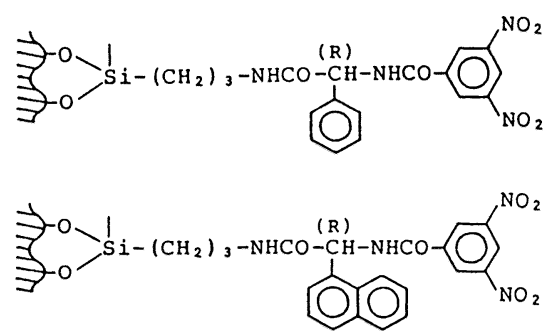

[II ]

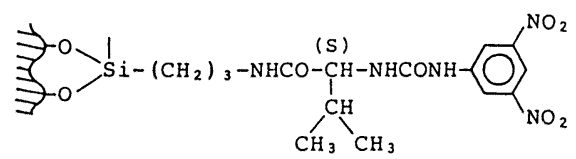

[II]

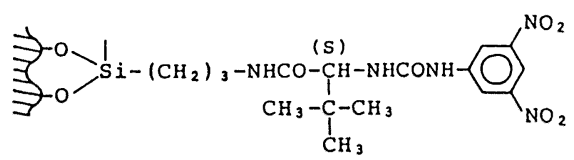
[IV]

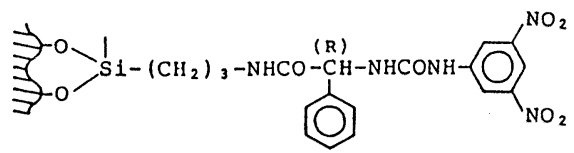

[V]

\section{$2 \cdot 1$ 試薬と装置}

誘導体化試薬として用いたダブシルクロライド及びピ レン-1-カルボニルニトリル, 並びにキラルカラム [I] [ [V] (スミキラル OA-2000, OA-2500, OA$3300, \mathrm{OA}-3200, \mathrm{OA}-3100$, 長さ $25 \mathrm{~cm}$, 内径 4.6 $\mathrm{mm}$, 住化分析センター製）はいずれも市販品をそのま ま使用した。その他の武薬，溶媒はいずれも市販の分析 用を用いた，装置には島津 LC-10A（UV, Vis 検出器) 及び日立 F-1050 型蛍光検出器などを使用した。 
Table 1 Enantiomer separation of $N$-dabsyl amino acids by HPLG with chiral columns

\begin{tabular}{|c|c|c|c|c|c|c|c|c|c|c|c|c|c|c|c|}
\hline \multirow{2}{*}{ Amino acid } & \multicolumn{3}{|c|}{ [III]SUMICHIRAL OA-3100 } & \multicolumn{3}{|c|}{ [IV]SUMICHIRAL OA-3200 } & \multicolumn{3}{|c|}{ [V]SUMICHIRAL OA- 3300} & \multicolumn{3}{|c|}{ [I] SUMICHIRAL OA-2000 } & \multicolumn{3}{|c|}{ [II] SUMICHIRAL OA-2500 } \\
\hline & $k_{1}^{\prime}$ & $k_{2}^{\prime}$ & $\alpha$ & $k_{1}^{\prime}$ & $k_{2}^{\prime}$ & $\alpha$ & $k_{1}^{\prime}$ & $k_{2}^{\prime}$ & $\alpha$ & $k_{1}^{\prime}$ & $k_{2}^{\prime}$ & $\alpha$ & $k_{1}^{\prime}$ & $k_{2}^{\prime}$ & $\bar{\alpha}$ \\
\hline & & 4. & 1.30 & & & & 0 & & & 2.04 & & 1.00 & 4.14 & & 1.00 \\
\hline Thr & 4. & 5.2 & 1.13 & 6.80 & & 1.09 & 12.55 & 14.44 & 1.15 & 4.14 & & 1.00 & 5.37 & 6.00 & 1.12 \\
\hline Proline & 8.32 & 9.08 & 1.09 & 12.44 & 13.99 & 1.12 & 25.10 & & 1.00 & 15.46 & 16.06 & 1.04 & 14.48 & 14.92 & 1.03 \\
\hline Phenylalanine & 4.17 & 5.26 & 1.26 & 4.88 & 7.17 & 1.47 & 10.86 & 12.59 & 1.16 & 5.70 & & 1.00 & 7.15 & 7.63 & 1.07 \\
\hline Lysine & 11.45 & 13.68 & 1.19 & 12.20 & 16.70 & 1.37 & 33.90 & 40.10 & 1.18 & 21.75 & . & 1.00 & 17.43 & 18.22 & 1.05 \\
\hline Glutamic acid & 6.46 & 7.88 & 1.22 & 7.84 & 8.58 & 1.09 & 16.18 & 19.47 & 1.20 & 13.00 & 14.86 & 1.14 & 10.60 & 11.21 & 1.06 \\
\hline
\end{tabular}

Mobile phase: $0.03 \mathrm{M}$ ammonium acetate in methanol. A flow-rate of $1.0 \mathrm{ml} / \mathrm{min}$ was used with a $250 \times 4.6 \mathrm{~mm}$ i.d. column at room temperature. $k_{1}{ }^{\prime}, k_{2}{ }^{\prime}$ : capacity factors of first- and second-eluted isomer; $\alpha$ : separation factor $\left(k_{2}{ }^{\prime} / k_{1}{ }^{\prime}\right)$

Table 2 Enantiomer separation of $N$-dabsyl amino acids by HPLC with chiral columns

\begin{tabular}{|c|c|c|c|c|c|c|}
\hline \multirow{2}{*}{ Amino acid } & \multicolumn{3}{|c|}{ [III]SUMICHIRAL OA-3100 } & \multicolumn{3}{|c|}{ [IV] SUMICHIRAL OA-3200 } \\
\hline & $k_{1}^{\prime}$ & $k_{2}^{\prime}$ & $\alpha$ & $k_{1}^{\prime}$ & $k_{2}^{\prime}$ & $\alpha$ \\
\hline Alanine & 3.99 & 4.88 & 1.22 & 4.84 & 6.51 & 1.35 \\
\hline Valine & 3.41 & 4.48 & 1.31 & 4.11 & 6.52 & 1.59 \\
\hline Leucine & 3.31 & 4.30 & 1.30 & 3.74 & 5.67 & 1.52 \\
\hline Isoleucine & 3.51 & 4.69 & 1.34 & 4.16 & 6.80 & 1.63 \\
\hline Phenylalanine & 4.17 & 5.26 & 1.26 & 4.88 & 7.17 & 1.47 \\
\hline Tyrosine & 12.11 & 14.76 & 1.22 & 13.90 & 19.02 & 1.37 \\
\hline Proline & 8.32 & 9.08 & 1.09 & 12.44 & 13.99 & 1.12 \\
\hline Methionine & 4.09 & 4.92 & 1.20 & 4.88 & 6.75 & 1.38 \\
\hline Serine & 6.01 & 6.90 & 1.15 & 8.73 & 10.32 & 1.18 \\
\hline Threonine & 4.73 & 5.33 & 1.13 & 6.80 & 7.44 & 1.09 \\
\hline Aspartic acid & 6.56 & 9.21 & 1.40 & 8.10 & 11.83 & 1.46 \\
\hline Glutamic acid & 6.46 & 7.88 & 1.22 & 7.84 & 8.58 & 1.09 \\
\hline Glutamine & 5.44 & 6.49 & 1.19 & 6.86 & 9.33 & 1.36 \\
\hline Lysine & 11.45 & 13.68 & 1.19 & 12.20 & 16.70 & 1.37 \\
\hline Arginine & 3.20 & 4.09 & 1.28 & 2.02 & 3.17 & 1.57 \\
\hline Histidine & 18.33 & 21.35 & 1.16 & 21.98 & 28.30 & 1.29 \\
\hline Tryptophan & 8.19 & 9.74 & 1.19 & 9.61 & 12.65 & 1.32 \\
\hline
\end{tabular}

Mobile phase: $0.03 \mathrm{M}$ ammonium acetate in methanol. A flow-rate of $1.0 \mathrm{ml} / \mathrm{min}$ was used with a $250 \times 4.6 \mathrm{~mm}$ i.d. column at room temperature. $k_{1}{ }^{\prime}, k_{2}{ }^{\prime}$ : capacity factors of first- and second-eluted isomer; $\alpha$ : separation factor $\left(k_{2}{ }^{\prime} / k_{1}{ }^{\prime}\right)$

\section{$2 \cdot 2$ 誘導体化と HPLC}

アミノ酸のダブシル化及びオキシ酸のピレン-1-カル ボニル化の反応は文献)6)記載の方法に準じて行った. 又, HPLC の条件は Table 1 に示した.

\section{3 結果と考察}

\section{$3 \cdot 1$ アミノ酸光学異性体の分離}

DL-ロイシンなど数種のアミノ酸のダブシル誘導体に ついて, 5 種のキラル固定相を用い光学異性体分離を
試みた結果は Table 1 に示すとおりで，キラル固定相 $[\mathrm{IV}]$ 及び $[\mathrm{V}]$ が優れた分離能を有することが認められ た. そこでこれらを用いて更に多数のアミノ酸の光学異 性体分離を検討したところ, Table 2 に示したようにほ ぼ満足すべき分離を得た.クロマトグラムの例を Fig. 1 に示す.なお, Fig. 1 の 10 分付近のピークについて は, 空試験の結果, ダブシルクロライド由来の不純物で あることを確認した。 


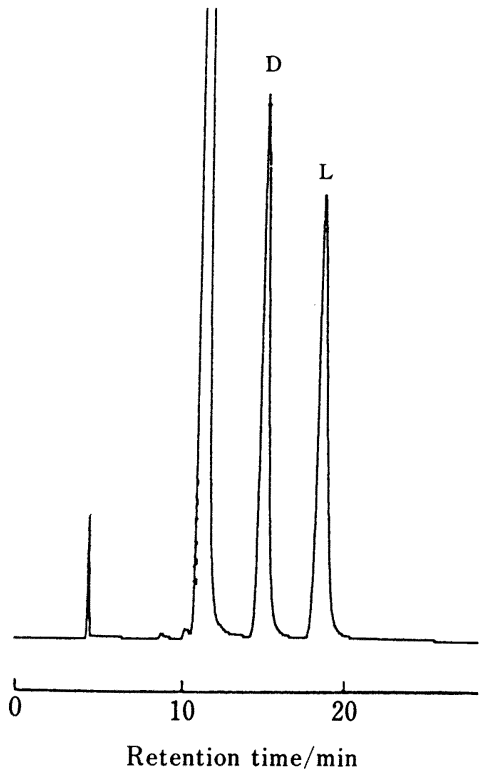

Fig. 1 Enantiomer separation of $N$-dabsyl-DLleucine with [III] (SUMICHIRAL OA-3100)

Chromatographic conditions as shown in Table 1.

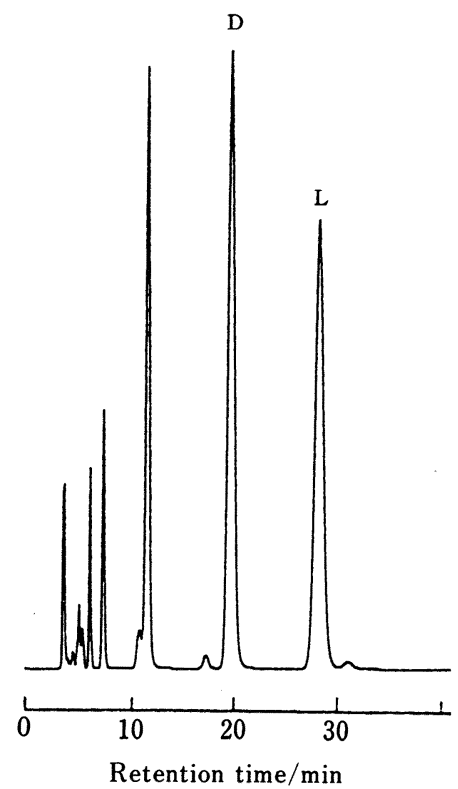

Fig. 2 Enantiomer separation of $O$-pyrene-1carbonyl-DL-lactic acid with [IV] (SUMICHIRAL OA-3200)

Chromatographic conditions as shown in Table 3.

Table 3 Enantiomer separation of $O$-pyren-1-carbonyl hydroxy acids by HPLC with chiral columns

\begin{tabular}{|c|c|c|c|c|c|c|c|c|}
\hline \multirow{2}{*}{ Chiral column } & \multicolumn{4}{|c|}{ Lactic acid } & \multicolumn{4}{|c|}{ Mandelic acid } \\
\hline & $k_{1}^{\prime}$ & $k_{2}^{\prime}$ & $\alpha$ & $\mathbf{M}$ & $k_{1}^{\prime}$ & $k_{2}^{\prime}$ & $\alpha$ & $\mathbf{M}$ \\
\hline [III]SUMICHIRAL OA-3100 & 3.85 & 4.70 & 1.22 & A & 3.21 & 4.33 & 1.35 & A \\
\hline [IV] SUMICHIRAL OA-3200 & 4.67 & 6.96 & 1.49 & A & 3.86 & 7.49 & 1.97 & A \\
\hline [ V ] SUMICHIRAL OA-3300 & 5.35 & 5.51 & 1.03 & A & 4.22 & 4.52 & 1.07 & A \\
\hline [ I ] SUMICHIRAL OA-2000 & 1.31 & 1.53 & 1.17 & A & 0.68 & 0.90 & 1.33 & A \\
\hline [II] SUMICHIRAL OA-2500 & 1.17 & 1.40 & 1.20 & A & 0.93 & 1.22 & 1.31 & A \\
\hline \multirow{2}{*}{ Chiral column } & \multicolumn{4}{|c|}{ 2-Hydroxybutyric acid } & \multicolumn{4}{|c|}{ Leucic acid } \\
\hline & $k_{1}^{\prime}$ & $k_{2}^{\prime}$ & $\alpha$ & $\mathbf{M}$ & $k_{1}^{\prime}$ & $k_{2}^{\prime}$ & $\alpha$ & $\mathbf{M}$ \\
\hline [III]SUMICHIRAL OA-3100 & 3.79 & 4.85 & 1.28 & A & 3.50 & 4.20 & 1.20 & A \\
\hline [IV] SUMICHIRAL OA-3200 & 5.23 & 9.00 & 1.72 & A & 5.26 & 8.15 & 1.55 & A \\
\hline
\end{tabular}

Mobile phase: (A) $0.1 \mathrm{M}$ ammonium acetate in [methanol/dioxane (50:50)]. A flow-rate of $1.0 \mathrm{ml} / \mathrm{min}$ was used with a $250 \times 4.6 \mathrm{~mm}$ i.d. column at room temperature. $k_{1}{ }^{\prime}, k_{2}{ }^{\prime}$ : capacity factors of first- and second-eluted isomer; $\alpha$ : separation factor $\left(k_{2}{ }^{\prime} / k_{1}{ }^{\prime}\right)$ 
Table 4 Detection limits

\begin{tabular}{|c|c|c|}
\hline & $\begin{array}{l}\text { Detection } \\
\text { limits/ } \\
\text { pmol }\end{array}$ & Detection \\
\hline$N$-Dabsyl-alanine & 2 & $\operatorname{Vis}(436 \mathrm{~nm})$ \\
\hline Alanine $^{\dagger}$ & 400 & $\mathrm{UV}(254 \mathrm{~nm})$ \\
\hline $\begin{array}{l}O \text {-Pyren-1-carbonyl- } \\
\text { lactic acid }\end{array}$ & 0.05 & $\begin{array}{l}\text { FL }(\text { Ex353 nm, Em393 } \\
\text { nm })\end{array}$ \\
\hline Lactic acid ${ }^{\dagger}$ & 400 & $\mathrm{UV}(254 \mathrm{~nm})$ \\
\hline
\end{tabular}

† Chiral ligand exchange method. HPLC conditions as in Tables 1 and 3. Detection was used fluorescence, visible or ultraviolet detection limits were calculated with $S / N=3$.

\section{$3 \cdot 2$ オキシ酸光学異性体の分離}

DL-乳酸及び DL-マンデル酸のピレン-1-カルボニル誘 導体について, 5 種のキラル固定相を用いて光学異性体 分離を試みた結果を Table 3 に示す.アミノ酸の場合と 同様に固定相 $[\mathrm{IV}]$ 及び $[\mathrm{V}]$ を用いるとき良好な分離 が得られた.クロマトグラムの例を Fig. 2 に示す.な お, Fig. 2 の 10 分付近のピークについては, 空試験の 結果, ピレン-1-カルボニルニトリル由来の不純物であ ることを確認した. DL-2-ヒドロキシ酪酸, DL-ロイシン 酸についても固定相 $[\mathrm{IV}]$ 及び $[\mathrm{V}]$ を用いて同様に満足 すべき分離を得た。

\section{3・3 検出限界}

DL-アラニンのダブシル誘導体について吸光光度法 $(436 \mathrm{~nm})$ により, 又 $\mathrm{DL}-$ 乳酸のピレン-1-カルボニル誘 導体について蛍光光度法 $(\mathrm{Ex} 353 \mathrm{~nm}, \mathrm{Em} 393 \mathrm{~nm})$ によ り検出限界 $(S / N=3)$ を求め, $N, S$-ジオクチル-(D)-ペ ニシラミンの銅錯体 ${ }^{2}$ （スミキラル OA-5000）を固定 相に用いるキラル配位子交換 HPLCにより, DL-アラ ニン及び $\mathrm{DL}$-乳酸を直接分離した場合の検出限界（吸光
光度法， $254 \mathrm{~nm}$ ）と比較した結果を Table 4 に示す.

誘導体としての分離では, 直接分離の場合に比べて, DL-アラニンにおいては約 200 倍, DL-乳酸においては約 8000 倍の検出感度が得られ, 微量のアミノ酸及びオキ シ酸光学異性体の分離のために本法が有効なことは明ら かである.

近年, HPLC において高感度検出のための誘導体化 試薬並びに光学異性体分離のためのキラル固定相の進歩 は共に目覚ましいものがあり，これらを組み合わせて利 用する方法はアミノ酸，才キシ酸に限らずアミン，アミ ノアルコール, カルボン酸等種々の光学異性体の微量分 析に極めて有用とみなされ, 今後の発展が期待される.

本研究の費用の一部は(財) ヒューマンサイエンス振興財 団の創薬科学総合研究事業の研究費によった.ここに記し て謝意を表します。

\section{$\left(\begin{array}{l}1994 \text { 年 } 6 \text { 月, 第 } 55 \text { 回分析化学 } \\ \text { 討論会において一部発表 }\end{array}\right)$}

\section{文献}

1) V. A. Davankov: Adv. Chromatogr., 15, 139 (1985).

2) N. Ôi, H. Kitahara, R. Kira: J. Chromatogr., 592, 291 (1992).

3) N. Ôi, H. Kitahara, F. Aoki: J. Chromatogr., 611, 177 (1993).

4) N. Ôi, H. Kitahara, F. Aoki: J. Liq. Chromatogr., 16, 893 (1993).

5) J. K. Lin, J. Y. Chang: Anal. Chem., 47, 1634 (1975).

6) J. Goto, S. Komatsu, M. Inada, T. Nambara: Anal. Sci., 2, 585 (1986).

7) W. H. Pirkle, I. M. Finn: J. Org. Chem., 46, 2935 (1981).

8) N. Ôi, H. Kitahara, Y. Matsumoto, H. Nakajima, Y. Horikawa: J. Chromatogr., 462, 382 (1989).

9) N. Ôi, H. Kitahara, F. Aoki, N. Kisu: J. Chromatogr., in press.

Enantiomer separation of small amounts of amino acids and hydroxy acids by HPLC using chiral stationary phases and achiral derivatizing reagents. Naobumi ÔI, Hajimu Kitahara and Naoko KIsu (Sumika Chemical Analysis Service, Ltd., 3-1-135, Kasugade-naka, Konohana-ku, Osaka-shi, Osaka 554)

The enantiomer separation of small amounts of amino acids and hydroxy acids by HPLC using chiral stationary phases and achiral derivatizing reagents was examined. Racemic dabsyl amino acids and pyrene-1-carbonyl hydroxy acids were well resolved on chiral stationary phases $[\mathrm{VI}]$ and $[\mathrm{V}]$, and excellent values of detection limits were 
obtained. The joint use of chiral stationary phases and achiral derivatizing reagents was found to be very effective for the separation and determination of small amounts of amino acid and hydroxy acid enantiomers by HPLC.

(Received November 14, 1994)

(Accepted January 9, 1995)

\section{Keyword phrases}

enantiomer separation; amino acids and hydroxy acids; HPLC; chiral stationary phase; achiral derivatizing reagent. 